\title{
A profile of drug resistance genes and integrons in $E$. coli causing surgical wound infections in the Faisalabad region of Pakistan
}

\author{
Muhammad Azeem Saeed, Abdul Haque, Aamir Ali, Mashkoor Mohsin, Saira Bashir, Ayesha Tariq, \\ Amna Afzal, Tayyaba Iftikhar and Yasra Sarwar
}

Escherichia coli are one of the leading causes of infection in wounds. Emerging multiple drug resistance among $E$. coli poses a serious challenge to antimicrobial therapy for wounds. This study was conducted to ascertain a baseline profile of antimicrobial resistance in $E$. coli isolates infecting surgical wounds. A total of 64 pus samples from hospitalized patients were screened and $29(45.3 \%)$ were found to have $E$. coli, which were identified biochemically and confirmed by molecular methods. Using the disc diffusion method, antimicrobial resistance was observed toward tetracycline (100\%), cefradine (100\%), nalidixic acid (93.1\%), ampicillin (86.2\%), gentamicin (86.2\%), cefixime $(82.8 \%)$, ceftriaxone $(82.8 \%)$, aztreonam $(82.8 \%)$, ciprofloxacin (75.9\%), streptomycin (72.4\%), cefoperazone (65.5\%), chloramphenicol (58.6\%) and amikacin (58.6\%). In an effort to find relevant genes, 11 different genes were targeted by PCR. Among these, the mutated gyrA gene was found to be the most prevalent (82.8\%), followed by the TEM (72.4\%), catP (68.9\%), catA1 (68.9\%), tetB (62.1\%), blt (58.6\%), blactX-M-15 (27.6\%), bla TEM $(20.7 \%)$, bla studied among these isolates. The prevalence of class 1 integrons was the highest (44.8\%), followed by class 2 (27.6\%). Three (10.3\%) isolates carried both class 1 and class 2 integrons (first report from $E$. coli infecting wounds). The high incidence of integrons points toward their facilitation for carriage of antimicrobial resistance genes; however, in nearly $37 \%$ isolates, no integrons were detected, indicating the significance of alternative mechanisms of gene transfer. Another salient finding was that all isolates were multidrug-resistant $E$. coli. The Journal of Antibiotics (2009) 62, 319-323; doi:10.1038/ja.2009.37; published online 15 May 2009

Keywords: drug resistance; E. coli; genetic elements; wounds

\section{INTRODUCTION}

Wounds may be community acquired or related to surgery. Medical practitioners combating wound infections often face a serious problem created by the presence of bacteria that are resistant to multiple antimicrobial drugs. Antimicrobial drug resistance complicates wound healing, lengthens the postoperative course and increases treatment costs. According to a report by the Center for Disease Control (CDC) in 1996, E. coli is the fourth most common pathogen implicated in surgical wound infections. ${ }^{1}$ However, depending on many socioeconomic factors, the prevalence and antimicrobial resistance patterns of E. coli also vary in wound specimens isolated from different regions around the globe. ${ }^{2}$ Multidrug-resistant (MDR) strains of $E$. coli pose a big challenge for the selection of antimicrobial drugs during treatment course. Plenty of economic and health losses occur every year because of all kinds of infections caused by extraintestinal E. coli, which include wound infections, neonatal meningitis, complicated urinary tract infections, spontaneous peritonitis, pneumonia, etc. In the United States alone, the total estimated cost associated with surgical wound infections is $1.2-4.0$ billion dollars per year, with an estimated E. coli-associated share of 94-252 million dollars per annum. ${ }^{1}$

It has been established that the spread of drug-resistance genes through horizontal routes has been a primary force in the swift evolution of resistance to a wide range of distinct drugs among various bacterial species. ${ }^{3}$ In addition to cross-resistance among antimicrobial drugs, there may be multiple genes conferring resistance to a single antimicrobial drug, and it may not be possible to explore all of them in a single study. Therefore, the results of phenotypic drug resistance (disc diffusion tests) and the molecular detection of respective genes may not always tally. ${ }^{3,4}$ Among the acquired mechanisms of resistance, the transfer of resistance determinants borne on plasmids, bacteriophages, transposons and particularly integrons is of utmost importance. Depending on the nature of the integrase, five classes of integrons have been documented to date, but three of them 
(particularly class 1) have clinical and epidemiological significance regarding antimicrobial resistance in human isolates. ${ }^{3}$ A critique of earlier studies revealed that $E$. coli readily transfer their mobile genetic elements to other $E$. coli and to strains of different genera, which could worsen the situation. ${ }^{5}$

In most developing countries, there is lack of information on the antimicrobial resistance patterns of E. coli infecting wounds. An extensive research work is needed to elucidate an overall profile of these wound-infecting $E$. coli in order to make an effective treatment strategy. The main objective of this study was to establish a baseline antimicrobial resistance profile of E. coli infecting wounds isolated from the local population.

\section{MATERIALS AND METHODS}

\section{Isolation and biochemical identification of $E$. coli}

Pus swabs were aseptically collected from wounds of 64 patients of all age groups and both sexes, admitted to the local hospitals of Faisalabad, Pakistan from January 2008 to April 2008. Each specimen was collected before an antiseptic application on the wound, using a sterile cotton swab, avoiding any contamination with the commensals of the skin. These specimens were transported to the laboratory in sterile conditions soon after collection. The specimens were streaked on MacConkey agar plates and incubated overnight at $37^{\circ} \mathrm{C}$ for the isolation of E. coli. Only a single isolate was processed from an individual patient. The isolates were subcultured on the same media for obtaining isolated colonies. For biochemical identification, these colonies were inoculated into triple sugar iron (TSI) agar slants in each case and results were interpreted according to the manufacturer's guidelines.

\section{DNA extraction}

Total genomic DNA from E. coli isolates was extracted from the overnight culture at $37^{\circ} \mathrm{C}$ in tryptic soy broth (TSB) using the phenol-chloroform method. ${ }^{6}$ The integrity of DNA samples was checked by electrophoresis on $1 \%$ agarose gel, and purity was determined by the ratio of A260/A280 spectrophotometrically. DNA samples were quantified with a fluorometer (DyNA Quant 200, Hoefer, Inc., Silver Spring, MD, USA).

\section{PCR for confirmation of $E$. coli}

The PCR was carried out for the confirmation of E. coli isolates by targeting the uidA gene for $\beta$-glucronidase using primers described earlier (Table 1). Each $100 \mu \mathrm{l}$ of the PCR reaction mixture contained, in addition to $20 \mathrm{ng}$ of template DNA, $1.5 \mathrm{~mm}$ of $\mathrm{MgCl}_{2}, 18 \mu \mathrm{M}$ of each dNTP, $0.8 \mu \mathrm{M}$ of each primer and $5 \mathrm{U}$ of $\mathrm{Taq}$ polymerase. The thermal cycler conditions were as follows: $94^{\circ} \mathrm{C}$ for $5 \mathrm{~min}$ (initial denaturation), followed by 30 cycles of $94^{\circ} \mathrm{C}$ for $1 \mathrm{~min}$, $50{ }^{\circ} \mathrm{C}$ for $1 \mathrm{~min}, 72^{\circ} \mathrm{C}$ for $1 \mathrm{~min}$ and a final extension of $72{ }^{\circ} \mathrm{C}$ for $7 \mathrm{~min}$.

\section{Antimicrobial susceptibility testing}

E. coli isolates confirmed by PCR were tested for their phenotypic susceptibility to seven major antimicrobial groups by the disc diffusion method, using discs of 13 representative antimicrobial drugs (Table 2). These antimicrobial drugs are currently in routine use for the treatment of different kinds of wounds in Pakistan. However, nalidixic acid was included only for comparison with ciprofloxacin. The results were interpreted following the guidelines of the Clinical and Laboratory Standards Institute (CLSI). ${ }^{7}$

\section{PCR for detection of integrons}

Class 1, 2 and 3 integrons (intI1, intI2 and intI3 genes, respectively) were targeted by PCR using earlier reported primer sets (Table 1). The thermal cycler conditions for intI1 and intI2 were as follows: $96^{\circ} \mathrm{C}$ for $30 \mathrm{~s}, 55^{\circ} \mathrm{C}$ for $1 \mathrm{~min}$ and $70{ }^{\circ} \mathrm{C}$ for $3 \mathrm{~min}$, followed by 25 cycles of $96^{\circ} \mathrm{C}$ for $15 \mathrm{~s}, 55^{\circ} \mathrm{C}$ for $30 \mathrm{~s}$ and $70{ }^{\circ} \mathrm{C}$ for $3 \mathrm{~min}$. PCR for intI 3 was performed at $94^{\circ} \mathrm{C}$ for $5 \mathrm{~min}$, followed by 30 cycles of $94^{\circ} \mathrm{C}$ for $2 \mathrm{~min}, 57^{\circ} \mathrm{C}$ for $1 \mathrm{~min}$ and $72^{\circ} \mathrm{C}$ for $1.5 \mathrm{~min}$. A final extension at $72^{\circ} \mathrm{C}$ for $7 \mathrm{~min}$ was performed at the end of each PCR.

For confirmation of the isolates carrying both class 1 and class 2 integrons, a multiplex PCR targeting both intI1 and intI2 genes simultaneously was also performed under the same thermal cycler conditions. Each $100 \mu \mathrm{l}$ of the PCR mixture for multiplex PCR contained, in addition to $20 \mathrm{ng}$ of DNA, $1.5 \mathrm{~mm}$ of $\mathrm{MgCl}_{2}, 70 \mu \mathrm{M}$ of each dNTP, $1.0 \mu \mathrm{M}$ of each primer and $10 \mathrm{U}$ of Taq polymerase.

\section{Restriction analyses of integrons}

To confirm the amplified products of class 1 and class 2 integrons, restriction endonucleases having their target sites in the amplified sequences of intI1 (AB365868) and intI2 (AJ001816) gene fragments from the nucleotide sequence database (GenBank) were selected. Endonucleases, NsbI and Eco521, were used to restrict the amplified products of class 1 integrons, whereas class 2 integron amplicons were restricted with $N s b$ I only. Each $30 \mu$ l of the restriction mixture contained $1 \mu \mathrm{l}(10 \mathrm{U})$ of enzyme, $8 \mu \mathrm{l}$ of PCR-amplified product, $3 \mu \mathrm{l}$ of enzyme buffer and $18 \mu \mathrm{l}$ of double-distilled water. Restriction mixtures were incubated at $37^{\circ} \mathrm{C}$ for $45 \mathrm{~min}$ and electrophoresed on $2 \%$ agarose gel.

\section{PCR for antimicrobial resistance genes}

The PCR was performed for the detection of 12 different antimicrobial resistance genes, using primer sets mentioned in Table 1. As no proper data are available regarding drug resistance genes from Pakistan, the studied genes were selected on the basis of their high prevalence worldwide to confer resistance against the used antimicrobial drugs in different $E$. coli isolates. PCR reaction mixture conditions were the same as those mentioned earlier for the uidA gene. Thermal cycler conditions for TEM, bla $a_{\mathrm{TEM}}, b l a_{\mathrm{OXA}}, c a t P$, bla $a_{\mathrm{CTX}-\mathrm{M}-15}$, cat $A$, tet $B$ and $b l t$ genes were as follows: $94^{\circ} \mathrm{C}$ for $5 \mathrm{~min}$, followed by 30 cycles of $94^{\circ} \mathrm{C}$ for $1 \mathrm{~min}, 51^{\circ} \mathrm{C}$ for $1 \mathrm{~min}$ and $72^{\circ} \mathrm{C}$ for $1 \mathrm{~min}$. PCR for the gyrA gene was conducted at $94^{\circ} \mathrm{C}$ for $5 \mathrm{~min}$, followed by 30 cycles of $94{ }^{\circ} \mathrm{C}$ for $1 \mathrm{~min}, 60^{\circ} \mathrm{C}$ for $1 \mathrm{~min}$ and $72^{\circ} \mathrm{C}$ for $1 \mathrm{~min}$. The conditions for amplification of the aadA1 and $\operatorname{aac}(3)-I$ genes were $94^{\circ} \mathrm{C}$ for $5 \mathrm{~min}$, followed by 30 cycles of $94^{\circ} \mathrm{C}$ for $30 \mathrm{~s}, 50^{\circ} \mathrm{C}$ for $30 \mathrm{~s}$ and $72^{\circ} \mathrm{C}$ for $1 \mathrm{~min}$, whereas for the tet $\mathrm{A}$ gene, the conditions were $94^{\circ} \mathrm{C}$ for $5 \mathrm{~min}$, followed by 30 cycles of $94^{\circ} \mathrm{C}$ for $30 \mathrm{~s}, 53^{\circ} \mathrm{C}$ for $30 \mathrm{~s}$ and $72^{\circ} \mathrm{C}$ for $1.5 \mathrm{~min}$. A final extension for $7 \mathrm{~min}$ at $72^{\circ} \mathrm{C}$ was performed at the end of each PCR. The amplified products were separated by electrophoresis on $2 \%$ agarose gels and photographed by UV transilluminator.

\section{RESULTS}

Biochemical and molecular detection of $E$. coli isolates Of the 64 pus samples, $29(45.3 \%)$ isolates were biochemically identified as E. coli in TSI agar slants. All these (29) isolates were confirmed as E. coli by PCR for the uidA gene.

\section{PCR and restriction analyses of integrons}

Class 1 integrons were the most prevalent, being found in 13 (44.8\%) isolates. Class 2 integrons were detected in eight (27.6\%) isolates, whereas all isolates were negative for class 3 integrons. Three (10.3\%) isolates were found to be carrying both class 1 and class 2 integrons, as confirmed by multiplex PCR also (Figure 1). Restriction of amplification products of the intI1 and intI2 genes generated the bands of expected sizes.

\section{Antimicrobial resistance profile}

For the sake of results interpretation, all isolates with intermediate susceptibility were regarded as resistant. ${ }^{5}$ The overall phenotypic and molecular drug resistance profile has been summarized in Table 2. By the disc diffusion method, all 29 (100\%) isolates showed resistance to at least three antimicrobial drugs belonging to structurally different antimicrobial groups; hence, all the isolates were considered as MDR. There were $28(96.6 \%)$ isolates that showed resistance to at least five drugs. A total of $22(75.9 \%)$ isolates were resistant to a minimum of 10 drugs and six $(20.7 \%)$ of the strains were found resistant to all drugs used.

Regarding $\beta$-lactam drugs, twenty-five (86.2\%) isolates were found resistant to ampicillin by the disc diffusion method. Three 
Table 1 Primer sets used in PCR

\begin{tabular}{|c|c|c|c|}
\hline Genes & Primer sequences $\left(5^{\prime}-3^{\prime}\right)$ & Amplicon size (bp) & References \\
\hline blaTEM & $\begin{array}{l}\text { ATGAGTATTCAACTTTCCGTGT } \\
\text { TTACCAATGCTTAATCAGTGACG }\end{array}$ & 876 & Chu et al. 25 \\
\hline gyrA & $\begin{array}{l}\text { TACCGTCATAGTTATCCACGA } \\
\text { GTACTTTACGCCATGAACGT }\end{array}$ & 342 & Molbak et al. ${ }^{27}$ \\
\hline catP & $\begin{array}{l}\text { CCTGCCACTCATCGCAGT } \\
\text { CACCGTTGATATATCCC }\end{array}$ & 623 & Guerra et al. ${ }^{28}$ \\
\hline $\operatorname{cat} A 1$ & $\begin{array}{l}\text { CGCCTGATGAATGCTCATCCG } \\
\text { CCTGCCACTCATCGCAGTAC }\end{array}$ & 457 & Molbak et al. ${ }^{27}$ \\
\hline blt & $\begin{array}{l}\text { CCCCTATTTGTTTATTTTTC } \\
\text { GACAGTTACCAATGCTTAAT }\end{array}$ & 962 & Yan et al..$^{29}$ \\
\hline blactX-M-15 & $\begin{array}{l}\text { AGAATAAGGAATCCCATGGTT } \\
\text { ACCGTCGGTGACGATTTTAG }\end{array}$ & 875 & Mendonca et al. ${ }^{30}$ \\
\hline $\operatorname{aad} A 1$ & $\begin{array}{l}\text { TGATTTGCTGGTTACGGTGAC } \\
\text { CGCTATGTTCTCTTGCTTTTG }\end{array}$ & 284 & Van et al. ${ }^{18}$ \\
\hline $\operatorname{aac}(3)-1$ & $\begin{array}{l}\text { ACCTACTCCCAACATCAGCC } \\
\text { ATATAGATCTCACTACGCGC }\end{array}$ & 157 & Van et al. ${ }^{18}$ \\
\hline int/1 & $\begin{array}{l}\text { ATCATCGTCGTAGAGACGTCGG } \\
\text { GTCAAGGTTCTGGACCAGTTGC }\end{array}$ & 892 & Rosser et al. ${ }^{31}$ \\
\hline int/2 & $\begin{array}{l}\text { GCAAATGAAGTGCAACGC } \\
\text { ACACGCTTGCTAACGATG }\end{array}$ & 467 & Rosser et al. ${ }^{31}$ \\
\hline
\end{tabular}

Table 2 Antimicrobial resistance profile of 29 isolates by disc diffusion and PCR

\begin{tabular}{|c|c|c|c|c|}
\hline Group isolates & Drug discs & Resistant n (\%) & Genes & Positive n (\%) \\
\hline \multirow[t]{2}{*}{ Tetracylins } & Tetracycline & 29 (100.0) & tet $B$ & $18(62.1)$ \\
\hline & & & tetA & $5(17.2)$ \\
\hline \multirow[t]{2}{*}{ Quinolones } & Nalidixic acid & $27(93.1)$ & & \\
\hline & Ciprofloxacin & $22(75.9)$ & gyrA & $24(82.8)$ \\
\hline \multirow[t]{3}{*}{ Aminoglycosides } & Gentamicin & $25(86.2)$ & $\operatorname{aac}(3)-1$ & $0(0)$ \\
\hline & Streptomycin & $21(72.4)$ & $\operatorname{aad} A 1$ & $4(13.8)$ \\
\hline & Amikacin & $17(58.6)$ & & \\
\hline \multirow[t]{2}{*}{ Phenicol derivatives } & Chloramphenicol & $17(58.6)$ & catA & 20 (68.9) \\
\hline & & & catP & $20(68.9)$ \\
\hline \multirow[t]{4}{*}{ Cephalosporins } & Cefradine & 29 (100.0) & blt & $17(58.6)$ \\
\hline & Cefixime & $24(82.4)$ & bla $a_{\mathrm{CTX}}-\mathrm{M}-15$ & $8(27.6)$ \\
\hline & Ceftriaxone & $24(82.4)$ & & \\
\hline & Cefoperazone & $19(65.5)$ & & \\
\hline \multirow[t]{3}{*}{ Penicillins } & Ampicillin & $25(86.2)$ & TEM & $21(72.4)$ \\
\hline & & & blaTEM & $5(17.2)$ \\
\hline & & & blaoxA & $5(17.2)$ \\
\hline Monobactam & Aztreonam & $24(82.4)$ & & \\
\hline
\end{tabular}

major genes responsible for conferring resistance to ampicillin were amplified: TEM in $21(72.4 \%), b l a_{\mathrm{TEM}}$ in $6(20.7 \%)$ and $b l a_{\mathrm{OXA}}$ in 5 $(17.2 \%)$ isolates. All isolates positive for $b l_{\mathrm{TEM}}$ were also found positive for the TEM gene. Among cephalosporins, 29 (100\%), 24 (82.8\%), $24(82.8 \%)$ and $19(65.5 \%)$ isolates showed resistance to cefradine, cefixime, ceftriaxone and cefoperazone, respectively. The related antimicrobial resistance genes, blt and $b l a_{\mathrm{CTX}-\mathrm{M}-15}$, were found in $17(58.6 \%)$ and eight (27.6\%) isolates, respectively. The majority of isolates, $24(82.8 \%)$, were resistant to monobactam (aztreonam).

Tetracycline resistance was observed in all 29 (100\%) isolates; the relevant resistance gene, tet $B$, was detected in 18 (62.1\%) isolates, followed by tet $A$ in five (17.2\%) isolates. One of the isolates was observed to have both $\operatorname{tet} A$ and $\operatorname{tet} B$ genes.

Chloramphenicol resistance was found in $15(62.5 \%)$, whereas chloramphenicol genes, catP and catA, were detected in $20(68.9 \%)$ isolates each; 17 (58.6\%) isolates carried both of these genes.

A total of $27(93.1 \%)$ isolates showed phenotypic resistance to nalidixic acid and $22(75.9 \%)$ to ciprofloxacin. A total of $24(82.4 \%)$ isolates were found to have a respective mutated gyrA gene.

In vitro resistance to aminoglycosides (gentamicin, streptomycin and amikacin) was found in 25 (86.2\%), 21 (72.4\%) and 17 (58.6\%) isolates, respectively. The gene, aadA1, responsible for imparting resistance against streptomycin, was found only in four $(13.8 \%)$ isolates; however, none of the isolates was found positive for the aac(3)-I gene specific to gentamicin.

In most isolates, a unique pattern of resistance genes was observed. However, three combinations were found in more than one isolate. 


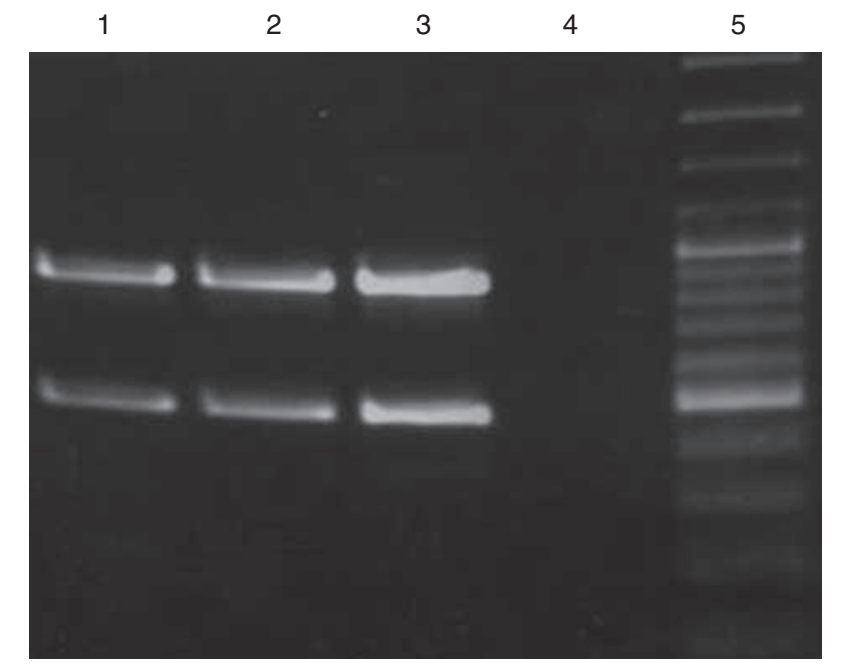

Figure 1 Multiplex PCR for integrons. Lane 1, 2 and 3: int/1 (upper band $=892 \mathrm{bp}$ ) and int/2 (lower band $=467 \mathrm{bp}$ ) in three different isolates; Lane 4: negative control PCR (PCR mix without template DNA); Lane 5: molecular weight marker (Fermentas SM0323; showing bands of 3000 , 2000, 1500, 1200, 1031, 900, 800, 700, 600, 500, 400, 300, 200 and $100 \mathrm{bp})$.

These were TEM, tet $B$, capP, cat $A$ and blt in eight (27.6\%) isolates, TEM, capP, catA and blt in four (13.8\%) and TEM, tetB, capP and cat $A$ in two $(6.9 \%)$ isolates.

\section{DISCUSSION}

Advancements to control wound infections have been hampered by the rapid emergence of antimicrobial resistance among bacterial population. However, there is a paucity of information with regard to antimicrobial resistance determinants in E. coli isolated from human wound infections, especially in developing countries. There are only few reports from Pakistan regarding antimicrobial resistance determinants in clinical isolates of $E$. coli at a molecular scale., ${ }^{8,9}$ There is no report that specifically deals with wound infections. This study was executed to analyze antimicrobial resistance of local E. coli isolates infecting surgical wounds, both at phenotypic and molecular levels.

One of the main mechanisms of drug resistance is gene transfer through integrons that are able to capture, integrate and express gene cassettes encoding antimicrobial resistance in clinical E. coli isolates. ${ }^{3}$ In our study, class 1 and 2 integrons were found in 44.8 and $27.6 \%$ isolates, respectively, whereas none of the isolates harbored class 3 integrons. Interestingly, $10.3 \%$ of the isolates were found to harbor both class 1 and 2 integrons. The simultaneous occurrence of two types of integrons in one E. coli isolate was significant, because it is relatively rare in clinical E. coli isolates. ${ }^{10-12}$ To our knowledge, it is the first time in the world that two types of integrons have been amplified simultaneously in wound-infecting E. coli. This highlights the increasing sophistication in the armory of these pathogens. The prevalence of integrons is relatively high as compared with some earlier reports, ${ }^{10,11}$ yet is comparable with a report from the United States. ${ }^{13}$ This high level of occurrence of integrons (62.6\%) highlights the threat of MDR. ${ }^{14}$

All our isolates showed resistance to at least three drugs, belonging to structurally different antimicrobial groups; hence, by definition, all the isolates could be classified as MDR.
We used ampicillin as representative of penicillins and found a high incidence of resistance $(86.2 \%)$ in our isolates (Table 2). It is in accordance with observations made by other researchers. ${ }^{15}$ There were $20.7 \%$ isolates resistant to ampicillin by the disc diffusion method, but were negative for the three most common genes involved in resistance against ampicillin (TEM, bla $a_{\mathrm{TEM}}$ and $b l a_{\mathrm{OXA}}$ genes). The drug resistance in these isolates may be related to several other genes that were not included in this study.

In $\beta$-lactams, cephalosporins constitute another major group. We used four drugs representing different generations of cephalosporins: cefradine (1st generation), cefixime and cefoperazone (2nd generation) and ceftriaxone (3rd generation). Interestingly, cefoperazone, not ceftriaxone, was the most effective drug (Table 2). However, the high sensitivity to cefoperazone $(34.5 \%)$ is not in line with some earlier reports. $^{15}$

Fluoroquinolones are perhaps the most important synthetic antimicrobial drugs used in clinical practice. Although there are several mechanisms for the development of resistance, mutation in the gyrA gene is the most common. ${ }^{16}$ The high occurrence of ciprofloxacin resistance $(75.9 \%)$ in our isolates is in accordance with some other reports from Asia, ${ }^{15,17}$ but it is in contrast to a report from Vietnam. ${ }^{18}$ As expected, the incidence of resistance to nalidixic acid, which is a simple quinolone, was higher $(93.1 \%)$ and in agreement with some earlier reports. ${ }^{4}$

Aminoglycosides are an important group of bactericidal drugs that are very effective against Gram-negative bacteria. We used amikacin, streptomycin and gentamicin as representatives of this group. Amikacin was the most effective drug, as $41.4 \%$ isolates were sensitive to it. These results are in accordance with earlier reports from Pakistan and India. ${ }^{15,19}$ The resistance to gentamicin (86.2\%) and streptomycin $(72.4 \%)$ was found to be relatively high as compared with some earlier reports. $4,15,19$

Tetracycline has been a widely used antimicrobial drug, but all of our isolates showed resistance to it. Similar results have been reported earlier from Vietnam. ${ }^{18}$ Twenty-two (75.9\%) isolates were positive for either one or both of the tet $A$ and tet $B$ genes. However, we found neither of these genes in $24.1 \%$ isolates. This may be due to some other resistance phenomenon not studied in this work such as efflux pumps. ${ }^{20}$

Chloramphenicol is a broad-spectrum bacteriostatic, inhibitor of protein synthesis that has utility in human clinical practice. Surprisingly, it was relatively the most effective drug (with $41.4 \%$ sensitivity) besides amikacin in our study. Similar results were documented previously, ${ }^{21}$ but Anguzu reported 100\% resistance against chloramphenicol in Uganda. ${ }^{2}$ This difference may be due to geographical disparity. However, it is interesting that five $(17.2 \%)$ isolates were having cat $P$ or cat $A$ genes, although they were sensitive to chloramphenicol by disc diffusion method. This indicates that genes may be silenced in these isolates due to many factors, including the reduced use of chloramphenicol in clinical practice because of its toxic effects. $^{22}$

We analyzed the data for the presence of multiple gene cassettes, which may indicate wholesome horizontal transfer of drug resistance. But generally speaking, this was not the case. In most isolates, a unique pattern of resistance genes was observed. However, three combinations encompassing 14 isolates were detected in more than one isolate. Details have been given in the Results section.

We conclude that MDR is very frequent in wound-infecting E. coli. In developing countries, the careless use of antimicrobial drugs by clinicians and easy access without prescription are the main factors. To date, very little work has been carried out on the antimicrobial 
resistance profile of $E$. coli infecting wounds at the molecular level, and more inputs are needed so that clinicians can be better equipped to cope with these infections.

1 Russo, T. A. \& Johnson, J. R. Medical and economic impact of extraintestinal infections due to Escherichia coli: focus on an increasingly important endemic problem. Microbes. Infect. 5, 449-456 (2003).

2 Anguzu, J. R. \& Olila, D. Drug sensitivity patterns of bacterial isolates from septic post-operative wounds in a regional referral hospital in Uganda. Afr. Health. Sci. 7, 148-154 (2007).

3 Rowe-Magnus, D. A. \& Mazel, D. The role of integrons in antibiotic resistance gene capture. Int. J. Med. Microbiol. 292, 115-125 (2002).

4 Srinivasan, V. et al. Characterization of antimicrobial resistance patterns and class 1 integrons in Escherichia coli $\mathrm{O} 26$ isolated from humans and animals. Int. J. Antimicrob. Agents. 29, 254-262 (2007).

5 Zhao, S. et al. Antimicrobial susceptibility and molecular characterization of avian pathogenic Escherichia coli isolates. Vet. Microbiol. 107, 215-224 (2005).

6 Sambrook, J., Fritsch, E. F. \& Maniatis, T. Molecular cloning: A laboratory manual (Cold Spring Harbor Laboratory Press, New York, 1989).

7 National Committe for Clinical Laboratory Standards. Performance standards for antimicrobial susceptibility testing. Fourth informational supplement. Document M100-S14 (NCCLS: Wayne, PA, 2004).

8 Shanahan, P. M., Karamat, K. A., Thomson, C. J. \& Amyes, S. G. Characterization of multi-drug resistant Salmonella typhi isolated from Pakistan. Epidemiol. Infect. 124, 9-16 (2000).

9 Hawkey, P. M. Prevalence and clonality of extended-spectrum beta-lactamases in Asia. Clin. Microbiol. Infect. 14 (Suppl 1), 159-165 (2008).

10 Reyes, A. et al. Prevalence and types of class 1 integrons in aminoglycosideresistant Enterobacteriaceae from several Chilean hospitals. J. Antimicrob. Chemother. 51, 317-321 (2003).

$11 \mathrm{Yu}, \mathrm{H}$. S. et al. Changes in gene cassettes of class 1 integrons among Escherichia coli isolates from urine specimens collected in Korea during the last two decades. J. Clin. Microbiol. 41, 5429-5433 (2003).

12 Mathai, E., Grape, M. \& Kronvall, G. Integrons and multidrug resistance among Escherichia coli causing community-acquired urinary tract infection in southern India. APMIS. 112, 159-164 (2004).

13 Solberg, O. D., Ajiboye, R. M. \& Riley, L. W. Origin of class 1 and 2 integrons and gene cassettes in a population-based sample of uropathogenic Escherichia coli. J. Clin. Microbiol. 44, 1347-1351 (2006).

14 Skurnik, D. et al. Integron-associated antibiotic resistance and phylogenetic grouping of Escherichia coli isolates from healthy subjects free of recent antibiotic exposure. Antimicrob. Agents. Chemother. 49, 3062-3065 (2005).

15 Nagoba, B. S. et al. A simple and effective approach for the treatment of chronic wound infections caused by multiple antibiotic resistant Escherichia coli. J. Hosp. Infect. 69, 177-180 (2008).
16 Piatti, G., Mannini, A., Balistreri, M. \& Schito, A. M. Virulence factors in urinary Escherichia coli strains: phylogenetic background and quinolone and fluoroquinolone resistance. J. Clin. Microbiol. 46, 480-487 (2008).

17 Mehrgan, H. \& Rahbar, M. Prevalence of extended-spectrum beta-lactamase-producing Escherichia coli in a tertiary care hospital in Tehran, Iran. Int. J. Antimicrob. Agents. 31, 147-151 (2008)

18 Van, T. T., Chin, J., Chapman, T., Tran, L. T. \& Coloe, P. J. Safety of raw meat and shellfish in Vietnam: an analysis of Escherichia coli isolations for antibiotic resistance and virulence genes. Int. J. Food. Microbiol. 124, 217-223 (2008).

19 Jabeen, K., Zafar, A. \& Hasan, R. Frequency and sensitivity pattern of extended spectrum beta lactamase producing isolates in a tertiary care hospital laboratory of Pakistan. J. Pak. Med. Assoc. 55, 436-439 (2005).

20 Guardabassi, L., Dijkshoorn, L., Collard, J. M., Olsen, J. E. \& Dalsgaard, A. Distribution and in-vitro transfer of tetracycline resistance determinants in clinical and aquatic Acinetobacter strains. J. Med. Microbiol. 49, 929-936 (2000).

21 Srinivasan, V., Nguyen, L. T., Headrick, S. I., Murinda, S. E. \& Oliver, S. P. Antimicrobial resistance patterns of Shiga toxin-producing Escherichia coli 0157:H7 and 0157:H7- from different origins. Microb. Drug. Resist. 13, 44-51 (2007).

22 Enne, V. I., Delsol, A. A., Roe, J. M. \& Bennett, P. M. Evidence of antibiotic resistance gene silencing in Escherichia coli. Antimicrob. Agents. Chemother. 50, 3003-3010 (2006).

23 Heininger, A. et al. PCR and blood culture for detection of Escherichia coli bacteremia in rats. J. Clin. Microbiol. 37, 2479-2482 (1999).

24 Carlson, S. A. et al. Detection of multiresistant Salmonella typhimurium DT104 using multiplex and fluorogenic PCR. Mol. Cell. Probes. 13, 213-222 (1999).

$25 \mathrm{Chu}, \mathrm{C}$. et al. Large drug resistance virulence plasmids of clinical isolates of Salmonella enterica serovar Choleraesuis. Antimicrob. Agents. Chemother. 45, 2299-2303 (2001).

26 Peirano, G., Agerso, Y., Aarestrup, F. M. \& dos Prazeres Rodrigues, D. Occurrence of integrons and resistance genes among sulphonamide-resistant Shigella spp. from Brazil. J. Antimicrob. Chemother. 55, 301-305 (2005).

27 Molbak, K. et al. An outbreak of multidrug-resistant, quinolone-resistant Salmonella enterica serotype typhimurium DT104. N. Engl. J. Med. 341, 1420-1425 (1999).

28 Guerra, B., Soto, S. M., Arguelles, J. M. \& Mendoza, M. C. Multidrug resistance is mediated by large plasmids carrying a class 1 integron in the emergent Salmonella enterica serotype [4,5,12:i:-]. Antimicrob. Agents. Chemother. 45, 1305-1308 (2001).

29 Yan, J. J. et al. Dissemination of CTX-M-3 and CMY-2 beta-lactamases among clinical isolates of Escherichia coli in southern Taiwan. J. Clin. Microbiol. 38, 4320-4325 (2000).

30 Mendonca, N., Leitao, J., Manageiro, V., Ferreira, E. \& Canica, M. Spread of extendedspectrum beta-lactamase CTX-M-producing Escherichia coli clinical isolates in community and nosocomial environments in Portugal. Antimicrob. Agents. Chemother. 51, 1946-1955 (2007).

31 Rosser, S. J. \& Young, H. K. Identification and characterization of class 1 integrons in bacteria from an aquatic environment. J. Antimicrob. Chemother. 44, 11-18 (1999).

32 Senda, K. et al. PCR detection of metallo-beta-lactamase gene (blalMP) in Gram-negative rods resistant to broad-spectrum beta-lactams. J. Clin Microbiol. 34, $2909-2913$ (1996). 